\title{
Iterative Methods for Equilibrium Problems and Monotone Inclusion Problems in Hilbert Spaces
}

\author{
Huan-chun Wu and Cao-zong Cheng \\ College of Applied Science, Beijing University of Technology, Beijing 100124, China \\ Correspondence should be addressed to Cao-zong Cheng; czcheng@bjut.edu.cn
}

Received 16 July 2013; Accepted 9 September 2013

Academic Editor: Shih-sen Chang

Copyright (C) 2013 H.-c. Wu and C.-z. Cheng. This is an open access article distributed under the Creative Commons Attribution License, which permits unrestricted use, distribution, and reproduction in any medium, provided the original work is properly cited.

We introduce a new iterative method for finding a common element of the set of solutions of an equilibrium problem and the set of zeros of the sum of maximal monotone operators, and we obtain strong convergence theorems in Hilbert spaces. We also apply our results to the variational inequality and convex minimization problems. Our results extend and improve the recent result of Takahashi et al. (2012).

\section{Introduction}

Let $H$ be a real Hilbert space and let $C$ be a nonempty closed convex subset of $H$. Let $f$ be a bifunction from $C \times C$ to $\mathbb{R}$, where $\mathbb{R}$ is the set of real numbers. The equilibrium problem for $f$ is to find $\bar{x} \in C$ such that

$$
f(\bar{x}, y) \geq 0 \quad \forall y \in C .
$$

The set of solutions of (1) is denoted by $E P(f)$. Numerous problems in physics, optimization, and economics are reduced to find the solution of an equilibrium problem (e.g., see [1]). For solving an equilibrium problem, we assume that the bifunction $f$ satisfies the following conditions:

(A1) $f(x, x)=0$ for all $x \in C$;

(A2) $f$ is monotone; that is, $f(x, y)+f(y, x) \leq 0$ for all $x, y \in C$;

(A3) for every $x, y, z \in C, \lim \sup _{t \downarrow} f(t z+(1-t) x, y) \leq$ $f(x, y)$;

(A4) $f(x, \cdot)$ is convex and lower semicontinuous for each $x \in C$.

Equilibrium problems have been studied extensively (see [16]).
Let $B$ be a mapping of $H$ into $2^{H}$. The effective domain of $B$ is denoted by $\operatorname{dom}(B)$; that is, $\operatorname{dom}(B)=\{x \in H: B x \neq \emptyset\}$. A multivalued mapping $B$ is said to be monotone if

$$
\langle x-y, u-v\rangle \geq 0 \quad \forall x, y \in \operatorname{dom}(B), u \in B x, v \in B y .
$$

A monotone operator $B$ is said to be maximal if its graph is not properly contained in the graph of any other monotone operator. For a maximal monotone operator $B$ on $H$ and $r>$ 0 , we may define a single-valued operator $J_{r}=(I+r B)^{-1}$ : $H \rightarrow \operatorname{dom}(B)$, which is called the resolvent of $B$ for $r$. It is known that $J_{r}$ is firmly nonexpansive. A basic problem for maximal monotone operator $B$ is to

$$
\text { find } x \in H \text { such that } 0 \in B x \text {. }
$$

The classical method for solving problem (3) is the proximal point algorithm. Rockafellar [7] established the weak convergence of the proximal point algorithm for maximal monotone operators. The question whether the strong convergence of the proximal point algorithm holds was answered in the negative by Güler [8]. In order to obtain the strong convergence theorem, some researchers have been devoted to modifying the proximal point algorithm (see $[9,10])$. Given a positive constant $\alpha$, a mapping $A: C \rightarrow H$ is said to be $\alpha$-inverse strongly monotone if

$$
\langle x-y, A x-A y\rangle \geq \alpha\|A x-A y\|^{2} \quad \forall x, y \in C .
$$


Generally, monotone inclusion problem is to

find $x \in C$ such that $0 \in(A+B) x$,

where the mapping $A: C \rightarrow H$ is inverse strongly monotone and $B$ is maximal monotone. We write $(A+B)^{-1} 0$ for the set of solutions of problem (5); that is, $(A+B)^{-1} 0=\{x \in C$ : $0 \in(A+B) x\}$. It is well known that $(A+B)^{-1} 0=\operatorname{Fix}\left(J_{\lambda}(I-\right.$ $\lambda A)$ ) (see [11]). Takahashi et al. [12] constructed the following iterative sequence. Let $u \in C, x_{1}=x \in C$ and let $\left\{x_{n}\right\}$ be a sequence generated by

$$
x_{n+1}=\beta_{n} x_{n}+\left(1-\beta_{n}\right)\left(\alpha_{n} u+\left(1-\alpha_{n}\right) J_{\lambda_{n}}\left(x_{n}-\lambda_{n} A x_{n}\right)\right) .
$$

Under appropriate conditions, they proved that the sequence $\left\{x_{n}\right\}$ converges strongly to a point $z_{0} \in(A+B)^{-1} 0$. Lin and Takahashi [13] introduced an iterative sequence that converges strongly to an element of $(A+B)^{-1} 0 \cap F^{-1} 0$, where $F$ is another maximal monotone operator.

Motivated by the above results, especially by Chuang et al. [2] and Takahashi et al. [12], we introduce a new iterative method for finding a common element of the set of solutions of an equilibrium problem and the set of zeros of the sum of maximal monotone operators, and we obtain strong convergence theorems in Hilbert spaces. We also apply our results to the variational inequality and convex minimization problems. Our results extend and improve the recent result of [12].

\section{Preliminaries}

Throughout this paper, let $H$ be a real Hilbert space with inner product $\langle\cdot, \cdot\rangle$ and norm $\|\cdot\|$ and let $C$ be a nonempty closed convex subset of $H$. A mapping $S: C \rightarrow H$ is nonexpansive if $\|S x-S y\| \leq\|x-y\|$ for all $x, y \in C$. The set of fixed points of $S$ is denoted by $\operatorname{Fix}(S)$; that is, $\operatorname{Fix}(S)=\{x \in C: S x=x\}$. It is well known that $\operatorname{Fix}(S)$ is closed and convex. We denote the strong convergence and the weak convergence of $\left\{x_{n}\right\}$ to $x$ by $x_{n} \rightarrow x$ and $x_{n} \rightarrow x$, respectively. For any $x \in H$, there exists a unique point $P_{C} x \in C$ such that

$$
\left\|x-P_{C} x\right\| \leq\|x-y\|, \quad \forall y \in C
$$

$P_{C}$ is called the metric projection of $H$ onto $C$. Note that $P_{C}$ is a nonexpansive mapping. For $x \in H$ and $z \in C$, we have

$$
z=P_{C} x \Longleftrightarrow\langle x-z, y-z\rangle \leq 0 \quad \text { for every } y \in C \text {. }
$$

Now consider inverse strongly monotone operators. For $\alpha>0$, let $A: C \rightarrow H$ be an $\alpha$-inverse strongly monotone operator. If $0<\lambda \leq 2 \alpha$, then $I-\lambda A$ is a nonexpansive mapping. Indeed, for $x, y \in C$ and $0<\lambda \leq 2 \alpha$, we get

$$
\begin{aligned}
\|(I-\lambda A) x-(I-\lambda A) y\|^{2} \\
\quad=\|(x-y)-\lambda(A x-A y)\|^{2} \\
\quad=\|x-y\|^{2}-2 \lambda\langle x-y, A x-A y\rangle+\lambda^{2}\|A x-A y\|^{2} \\
\quad \leq\|x-y\|^{2}-2 \lambda \alpha\|A x-A y\|^{2}+\lambda^{2}\|A x-A y\|^{2} \\
\quad \leq\|x-y\|^{2}+\lambda(\lambda-2 \alpha)\|A x-A y\|^{2} \leq\|x-y\|^{2} .
\end{aligned}
$$

Therefore, the operator $I-\lambda A$ is a nonexpansive mapping of $C$ into $H$.

We collect some important facts and tools.

Lemma 1 (see [1]). Let $C$ be a nonempty closed convex subset of $H$ and let $f$ be a bifunction from $C \times C$ to $\mathbb{R}$ satisfying (A1)(A4). If $r>0$ and $x \in H$, then there exists $z \in C$ such that

$$
f(z, y)+\frac{1}{r}\langle y-z, z-x\rangle \geq 0 \quad \forall y \in C .
$$

Lemma 2 (see [4]). Let $C$ be a nonempty closed convex subset of $H$, and let $f$ be a bifunction from $C \times C$ to $\mathbb{R}$ satisfying (A1)(A4). For $r>0$, define a mapping $T_{r}: H \rightarrow 2^{C}$ as follows:

$$
\begin{aligned}
& T_{r}(x) \\
& \quad=\left\{z \in C: f(z, y)+\frac{1}{r}\langle y-z, z-x\rangle \geq 0 \forall y \in C\right\} .
\end{aligned}
$$

Then, the following hold:

(i) $T_{r}$ is single valued;

(ii) $T_{r}$ is firmly nonexpansive; that is, for any $x, y \in H$, $\left\langle x-y, T_{r} x-T_{r} y\right\rangle \geq\left\|T_{r} x-T_{r} y\right\|^{2}$

(iii) $\operatorname{Fix}\left(T_{r}\right)=E P(f)$;

(iv) $E P(f)$ is closed and convex.

Lemma 3 (see [6]). Suppose that (A1)-(A4) hold. If $x, y \in H$ and $r_{1}, r_{2}>0$, then

$$
\left\|T_{r_{2}} y-T_{r_{1}} x\right\| \leq\|y-x\|+\frac{\left|r_{2}-r_{1}\right|}{r_{2}}\left\|T_{r_{2}} y-y\right\| .
$$

Lemma 4 (see [14]). Let $H$ be a real Hilbert space and let $B$ be a maximal monotone operator on $H$. Then, the following holds:

$$
\frac{s-t}{s}\left\langle J_{s} x-J_{t} x, J_{s} x-x\right\rangle \geq\left\|J_{s} x-J_{t} x\right\|^{2}
$$

for all $s, t>0$ and $x \in H$.

Lemma 5 (see [15]). Let $\left\{x_{n}\right\}$ and $\left\{y_{n}\right\}$ be bounded sequences in a Banach space $X$ and let $\left\{\beta_{n}\right\}$ be a sequence in $[0,1]$ with $0<\liminf _{n \rightarrow \infty} \beta_{n} \leq \lim \sup _{n \rightarrow \infty} \beta_{n}<1$. Suppose $x_{n+1}=$ $\left(1-\beta_{n}\right) x_{n}+\beta_{n} y_{n}$ for all integers $n \geq 1$ and $\lim \sup _{n \rightarrow \infty}\left(\| y_{n+1}-\right.$ $\left.y_{n}\|-\| x_{n+1}-x_{n} \|\right) \leq 0$. Then, $\lim _{n \rightarrow \infty}\left\|y_{n}-x_{n}\right\|=0$. 
The following lemma is an immediate consequence of the inner product on $H$.

Lemma 6. For all $x, y \in H$, the inequality $\|x+y\|^{2} \leq\|x\|^{2}+$ $2\langle y, x+y\rangle$ holds.

Lemma 7 (demiclosedness principle [16]). Let $C$ be a nonempty closed convex subset of $H$ and $S: C \rightarrow H a$ nonexpansive mapping. Let $x$ be a point in $H$ and let $\left\{x_{n}\right\}$ be a sequence in C. Suppose that $x_{n} \rightarrow x$ and that $x_{n}-S x_{n} \rightarrow 0$. Then, $x \in \operatorname{Fix}(S)$.

Lemma 8 (see [17]). Let $\left\{a_{n}\right\}$ be a sequence of nonnegative real numbers satisfying $a_{n+1} \leq\left(1-\alpha_{n}\right) a_{n}+\alpha_{n} \beta_{n}$, where

(i) $\left\{\alpha_{n}\right\} \subset(0,1), \sum_{n=1}^{\infty} \alpha_{n}=\infty$;

(ii) $\lim \sup _{n \rightarrow \infty} \beta_{n} \leq 0$.

Then, $\lim _{n \rightarrow \infty} a_{n}=0$.

\section{Strong Convergence Theorems}

In this section, we introduce a new iterative method for finding a common element of the set of zeros of the sum of maximal monotone operators and the set of solutions of an equilibrium problem, and we prove the strong convergence theorems in Hilbert spaces.

Theorem 9. Let $C$ be a nonempty closed convex subset of a real Hilbert space $H$ and $A$ an $\alpha$-inverse strongly monotone operator of $C$ into $H$ with $\alpha>0$. Suppose that $B$ is a maximal monotone operator on $H$ and $f$ is a bifunction from $C \times C$ to $\mathbb{R}$ with (A1)-(A4). Assume that $\Omega:=E P(f) \cap(A+B)^{-1} 0 \neq \emptyset$. Let $\left\{\alpha_{n}\right\}$ and $\left\{\beta_{n}\right\}$ be sequences in $(0,1)$ and let $\left\{u_{n}\right\}$ be a sequence in $H$. Let $\left\{x_{n}\right\}$ be a sequence generated by

$$
\begin{gathered}
x_{1} \in C \text { chosen arbitrarily, } \\
y_{n}=\alpha_{n} u_{n}+\left(1-\alpha_{n}\right) J_{\lambda_{n}}\left(I-\lambda_{n} A\right) x_{n}, \\
z_{n} \in C \text {, such that } f\left(z_{n}, y\right)+\frac{1}{r_{n}}\left\langle y-z_{n}, z_{n}-y_{n}\right\rangle \geq 0 \\
\quad \forall y \in C, \\
x_{n+1}=\beta_{n} x_{n}+\left(1-\beta_{n}\right) z_{n} .
\end{gathered}
$$

Assume the following conditions are satisfied:

(c1) $\lim _{n \rightarrow \infty} u_{n}=u$ for some $u \in H$;

(c2) $\lim _{n \rightarrow \infty} \alpha_{n}=0$ and $\sum_{n=1}^{\infty} \alpha_{n}=\infty$;

(c3) $0<\liminf _{n \rightarrow \infty} \beta_{n} \leq \lim \sup _{n \rightarrow \infty} \beta_{n}<1$;

(c4) $0<d \leq r_{n}<\infty$ and $\lim _{n \rightarrow \infty}\left(r_{n+1}-r_{n}\right)=0$;

(c5) $0<a \leq \lambda_{n} \leq 2 \alpha$ and $\lim _{n \rightarrow \infty}\left(\lambda_{n+1}-\lambda_{n}\right)=0$.

Then, the sequence $\left\{x_{n}\right\}$ converges strongly to $P_{\Omega} u$.

Proof. Note that the set $\Omega$ is closed and convex since $(A+$ $B)^{-1} 0$ and $E P(f)$ are closed and convex.
With the help of Lemmas 1 and 2, we have $z_{n}=T_{r_{n}} y_{n}$, and, for any $\omega \in \Omega$,

$$
\left\|z_{n}-\omega\right\|=\left\|T_{r_{n}} y_{n}-T_{r_{n}} \omega\right\| \leq\left\|y_{n}-\omega\right\| .
$$

Notice that

$$
\begin{aligned}
\left\|y_{n}-\omega\right\| & \leq \alpha_{n}\left\|u_{n}-\omega\right\|+\left(1-\alpha_{n}\right)\left\|J_{\lambda_{n}}\left(I-\lambda_{n} A\right) x_{n}-\omega\right\| \\
& \leq \alpha_{n}\left\|u_{n}-\omega\right\|+\left(1-\alpha_{n}\right)\left\|x_{n}-\omega\right\| .
\end{aligned}
$$

It follows that

$$
\begin{aligned}
\left\|x_{n+1}-\omega\right\|= & \left\|\beta_{n}\left(x_{n}-\omega\right)+\left(1-\beta_{n}\right)\left(z_{n}-\omega\right)\right\| \\
\leq & \beta_{n}\left\|x_{n}-\omega\right\|+\left(1-\beta_{n}\right) \\
& \times\left[\alpha_{n}\left\|u_{n}-\omega\right\|+\left(1-\alpha_{n}\right)\left\|x_{n}-\omega\right\|\right] \\
\leq & {\left[1-\alpha_{n}\left(1-\beta_{n}\right)\right]\left\|x_{n}-\omega\right\| } \\
& +\alpha_{n}\left(1-\beta_{n}\right)\left\|u_{n}-\omega\right\| \\
\leq & \max \left\{\left\|x_{n}-\omega\right\|,\left\|u_{n}-\omega\right\|\right\} .
\end{aligned}
$$

By condition (c1), the sequence $\left\{u_{n}\right\}$ is bounded. Hence, there exists a positive number $M$ such that $\sup _{n}\left\{\left\|u_{n}-\omega\right\|\right\} \leq M$. From a simple inductive process, we have

$$
\left\|x_{n+1}-\omega\right\| \leq \max \left\{\left\|x_{1}-\omega\right\|, M\right\},
$$

which yields that $\left\{x_{n}\right\}$ is bounded. So are $\left\{y_{n}\right\}$ and $\left\{z_{n}\right\}$.

We have from Lemmas 3 and 4 that

$$
\begin{aligned}
\left\|z_{n+1}-z_{n}\right\|= & \left\|T_{r_{n+1}} y_{n+1}-T_{r_{n}} y_{n}\right\| \\
\leq & \left\|y_{n+1}-y_{n}\right\|+\frac{\left|r_{n+1}-r_{n}\right|}{r_{n+1}}\left\|T_{r_{n+1}} y_{n+1}-y_{n+1}\right\| \\
\leq & \| \alpha_{n+1} u_{n+1}+\left(1-\alpha_{n+1}\right) J_{\lambda_{n+1}}\left(I-\lambda_{n+1} A\right) x_{n+1} \\
& -\alpha_{n} u_{n}-\left(1-\alpha_{n}\right) J_{\lambda_{n}}\left(I-\lambda_{n} A\right) x_{n} \| \\
& +\frac{\left|r_{n+1}-r_{n}\right|}{r_{n+1}}\left\|T_{r_{n+1}} y_{n+1}-y_{n+1}\right\| \\
\leq & \left\|J_{\lambda_{n+1}}\left(I-\lambda_{n+1} A\right) x_{n+1}-J_{\lambda_{n}}\left(I-\lambda_{n} A\right) x_{n}\right\| \\
& +\alpha_{n+1}\left[\left\|u_{n+1}\right\|+\left\|J_{\lambda_{n+1}}\left(I-\lambda_{n+1} A\right) x_{n+1}\right\|\right] \\
& +\alpha_{n}\left[\left\|u_{n}\right\|+\left\|J_{\lambda_{n}}\left(I-\lambda_{n} A\right) x_{n}\right\|\right] \\
& +\frac{\left|r_{n+1}-r_{n}\right|}{r_{n+1}}\left\|T_{r_{n+1}} y_{n+1}-y_{n+1}\right\| \\
\leq & \| J_{\lambda_{n+1}}\left(I-\lambda_{n+1} A\right) x_{n+1}-J_{\lambda_{n+1}}\left(I-\lambda_{n+1} A\right) x_{n} \\
& +J_{\lambda_{n+1}}\left(I-\lambda_{n+1} A\right) x_{n}-J_{\lambda_{n+1}}\left(I-\lambda_{n} A\right) x_{n} \\
& +J_{\lambda_{n+1}}\left(I-\lambda_{n} A\right) x_{n}-J_{\lambda_{n}}\left(I-\lambda_{n} A\right) x_{n} \|
\end{aligned}
$$




$$
\begin{aligned}
& +\alpha_{n+1}\left[\left\|u_{n+1}\right\|+\left\|J_{\lambda_{n+1}}\left(I-\lambda_{n+1} A\right) x_{n+1}\right\|\right] \\
& +\alpha_{n}\left[\left\|u_{n}\right\|+\left\|J_{\lambda_{n}}\left(I-\lambda_{n} A\right) x_{n}\right\|\right] \\
& +\frac{\left|r_{n+1}-r_{n}\right|}{r_{n+1}}\left\|T_{r_{n+1}} y_{n+1}-y_{n+1}\right\| \\
& \leq\left\|x_{n+1}-x_{n}\right\|+\left|\lambda_{n+1}-\lambda_{n}\right|\left\|A x_{n}\right\|+\frac{\left|\lambda_{n+1}-\lambda_{n}\right|}{a} \\
& \times\left\|J_{\lambda_{n+1}}\left(I-\lambda_{n} A\right) x_{n}-\left(I-\lambda_{n} A\right) x_{n}\right\| \\
& +\alpha_{n+1}\left[\left\|u_{n+1}\right\|+\left\|J_{\lambda_{n+1}}\left(I-\lambda_{n+1} A\right) x_{n+1}\right\|\right] \\
& +\alpha_{n}\left[\left\|u_{n}\right\|+\left\|J_{\lambda_{n}}\left(I-\lambda_{n} A\right) x_{n}\right\|\right] \\
& +\frac{\left|r_{n+1}-r_{n}\right|}{d}\left\|T_{r_{n+1}} y_{n+1}-y_{n+1}\right\| .
\end{aligned}
$$

Thus, conditions (c2), (c4), and (c5) yield that

$$
\limsup _{n \rightarrow \infty}\left(\left\|z_{n+1}-z_{n}\right\|-\left\|x_{n+1}-x_{n}\right\|\right) \leq 0 .
$$

Recall that $x_{n+1}=\beta_{n} x_{n}+\left(1-\beta_{n}\right) z_{n}$. It follows from Lemma 5 that

$$
\lim _{n \rightarrow \infty}\left\|z_{n}-x_{n}\right\|=0
$$

Consequently,

$$
\lim _{n \rightarrow \infty}\left\|x_{n+1}-x_{n}\right\|=\lim _{n \rightarrow \infty}\left(1-\beta_{n}\right)\left\|x_{n}-z_{n}\right\|=0 .
$$

For any $\omega \in \Omega$, according to Lemma 2, we have

$$
\begin{aligned}
\left\|z_{n}-\omega\right\|^{2} & =\left\|T_{r_{n}} y_{n}-T_{r_{n}} \omega\right\|^{2} \leq\left\langle y_{n}-\omega, z_{n}-\omega\right\rangle \\
& =\frac{1}{2}\left[\left\|y_{n}-\omega\right\|^{2}+\left\|z_{n}-\omega\right\|^{2}-\left\|y_{n}-z_{n}\right\|^{2}\right],
\end{aligned}
$$

which yields that

$$
\left\|z_{n}-\omega\right\|^{2} \leq\left\|y_{n}-\omega\right\|^{2}-\left\|z_{n}-y_{n}\right\|^{2}
$$

By (14), one has

$$
\begin{aligned}
\left\|x_{n+1}-\omega\right\|^{2}= & \left\|\beta_{n} x_{n}+\left(1-\beta_{n}\right) z_{n}-\omega\right\|^{2} \\
\leq & \beta_{n}\left\|x_{n}-\omega\right\|^{2}+\left(1-\beta_{n}\right)\left\|z_{n}-\omega\right\|^{2} \\
\leq & \beta_{n}\left\|x_{n}-\omega\right\|^{2}+\left(1-\beta_{n}\right) \\
& \times\left[\left\|y_{n}-\omega\right\|^{2}-\left\|z_{n}-y_{n}\right\|^{2}\right] \\
\leq & \beta_{n}\left\|x_{n}-\omega\right\|^{2}+\left(1-\beta_{n}\right) \\
& \times\left[\alpha_{n}\left\|u_{n}-\omega\right\|^{2}+\left(1-\alpha_{n}\right)\left\|x_{n}-\omega\right\|^{2}\right. \\
& \left.\quad-\left\|z_{n}-y_{n}\right\|^{2}\right] \\
\leq & {\left[1-\alpha_{n}\left(1-\beta_{n}\right)\right]\left\|x_{n}-\omega\right\|^{2} } \\
& +\alpha_{n}\left(1-\beta_{n}\right)\left\|u_{n}-\omega\right\|^{2}-\left(1-\beta_{n}\right)\left\|z_{n}-y_{n}\right\|^{2},
\end{aligned}
$$

which implies that

$$
\begin{aligned}
& \left(1-\beta_{n}\right)\left\|z_{n}-y_{n}\right\|^{2} \\
& \leq\left\|x_{n}-\omega\right\|^{2}-\left\|x_{n+1}-\omega\right\|^{2} \\
& \quad+\alpha_{n}\left(1-\beta_{n}\right)\left\|u_{n}-\omega\right\|^{2} \\
& \leq\left\|x_{n}-x_{n+1}\right\|\left(\left\|x_{n}-\omega\right\|+\left\|x_{n+1}-\omega\right\|\right) \\
& \quad+\alpha_{n}\left(1-\beta_{n}\right)\left\|u_{n}-\omega\right\|^{2} .
\end{aligned}
$$

This together with (22) deduces that

$$
\lim _{n \rightarrow \infty}\left\|z_{n}-y_{n}\right\|=0 .
$$

Next, we prove that

$$
\limsup _{n \rightarrow \infty}\left\langle u-\bar{x}, x_{n}-\bar{x}\right\rangle \leq 0
$$

where $\bar{x}=P_{\Omega} u$. In order to show this inequality, we can choose a subsequence $\left\{x_{n_{i}}\right\}$ of $\left\{x_{n}\right\}$ such that

$$
\limsup _{n \rightarrow \infty}\left\langle u-\bar{x}, x_{n}-\bar{x}\right\rangle=\lim _{i \rightarrow \infty}\left\langle u-\bar{x}, x_{n_{i}}-\bar{x}\right\rangle .
$$

Owing to the boundedness of $\left\{x_{n_{i}}\right\}$, without loss of generality, we assume that $x_{n_{i}} \rightarrow p$. Now we show that $p \in \Omega$. As $\left\{x_{n}\right\}$ is contained in $C$ and $C$ is a closed convex set, one has $p \in C$.

We firstly prove that $p \in E P(f)$. By (14), we have

$$
f\left(z_{n}, y\right)+\frac{1}{r_{n}}\left\langle y-z_{n}, z_{n}-y_{n}\right\rangle \geq 0, \quad \forall y \in C .
$$

The monotonicity of $f$ yields that

$$
\frac{1}{r_{n}}\left\langle y-z_{n}, z_{n}-y_{n}\right\rangle \geq f\left(y, z_{n}\right), \quad \forall y \in C .
$$

Replacing $n$ by $n_{i}$, we obtain

$$
\left\langle y-z_{n_{i}}, \frac{z_{n_{i}}-y_{n_{i}}}{r_{n_{i}}}\right\rangle \geq f\left(y, z_{n_{i}}\right), \quad \forall y \in C .
$$

It follows from (21), (27), and (A4) that

$$
f(y, p) \leq 0, \quad \forall y \in C .
$$

For $0<t \leq 1, y \in C$, set $y_{t}=t y+(1-t) p$. Then, $y_{t} \in C$ and $f\left(y_{t}, p\right) \leq 0$. Thus,

$$
0=f\left(y_{t}, y_{t}\right) \leq t f\left(y_{t}, y\right)+(1-t) f\left(y_{t}, p\right) \leq t f\left(y_{t}, y\right) .
$$

Dividing by $t$, we see that

$$
f\left(y_{t}, y\right) \geq 0 \text {. }
$$

Letting $t \downarrow 0$, we get

$$
f(p, y) \geq 0, \quad \forall y \in C ;
$$

namely, $p \in E P(f)$. 
Secondly, we prove that $p \in(A+B)^{-1} 0$. Thanks to (c5), there is a subsequence $\left\{\lambda_{n_{i_{j}}}\right\}$ of $\left\{\lambda_{n_{i}}\right\}$ such that $\lambda_{n_{i_{j}}} \rightarrow \lambda_{0} \in$ $[a, 2 \alpha]$. Without loss of generality, we assume that $\lambda_{n_{i}} \rightarrow \lambda_{0}$. Observe that

$$
\begin{aligned}
\| x_{n_{i}}- & J_{\lambda_{0}}\left(I-\lambda_{0} A\right) x_{n_{i}} \| \\
\leq & \left\|x_{n_{i}}-y_{n_{i}}\right\| \\
& +\left\|y_{n_{i}}-\left[\alpha_{n_{i}} u_{n_{i}}+\left(1-\alpha_{n_{i}}\right) J_{\lambda_{0}}\left(I-\lambda_{0} A\right) x_{n_{i}}\right]\right\| \\
& +\| \alpha_{n_{i}} u_{n_{i}}+\left(1-\alpha_{n_{i}}\right) J_{\lambda_{0}}\left(I-\lambda_{0} A\right) x_{n_{i}} \\
& \quad-J_{\lambda_{0}}\left(I-\lambda_{0} A\right) x_{n_{i}} \| \\
\leq & \left\|x_{n_{i}}-y_{n_{i}}\right\|+\left(1-\alpha_{n_{i}}\right) \\
& \times\left\|J_{\lambda_{n_{i}}}\left(I-\lambda_{n_{i}} A\right) x_{n_{i}}-J_{\lambda_{0}}\left(I-\lambda_{0} A\right) x_{n_{i}}\right\| \\
& +\alpha_{n_{i}}\left\|u_{n_{i}}-J_{\lambda_{0}}\left(I-\lambda_{0} A\right) x_{n_{i}}\right\| \\
\leq & \left\|x_{n_{i}}-y_{n_{i}}\right\|+\left(1-\alpha_{n_{i}}\right) \\
& \times\left[\left\|J_{\lambda_{n_{i}}}\left(I-\lambda_{n_{i}} A\right) x_{n_{i}}-J_{\lambda_{n_{0}}}\left(I-\lambda_{n_{i}} A\right) x_{n_{i}}\right\|\right. \\
& \left.+\left\|J_{\lambda_{n_{0}}}\left(I-\lambda_{n_{i}} A\right) x_{n_{i}}-J_{\lambda_{n_{0}}}\left(I-\lambda_{n_{0}} A\right) x_{n_{i}}\right\|\right] \\
& +\alpha_{n_{i}}\left\|u_{n_{i}}-J_{\lambda_{0}}\left(I-\lambda_{0} A\right) x_{n_{i}}\right\| \\
\leq & \left\|x_{n_{i}}-y_{n_{i}}\right\|+\left(1-\alpha_{n_{i}}\right) \\
& \times\left[\frac{\left|\lambda_{0}-\lambda_{n_{i}}\right|\left\|J_{n_{n_{0}}}\left(I-\lambda_{n_{i}} A\right) x_{n_{i}}-\left(I-\lambda_{n_{i}} A\right) x_{n_{i}}\right\|}{\lambda_{0}}\right. \\
& \left.+\left|\lambda_{n_{n_{i}}}-J_{n_{n_{0}}}\right|\left\|A x_{n_{i}}\right\|\right] \\
& \left(I-\lambda_{0} A\right) x_{n_{i}} \| .
\end{aligned}
$$

Note that expressions (21) and (27) imply that

$$
\lim _{n \rightarrow \infty}\left\|x_{n}-y_{n}\right\|=0 \text {. }
$$

Therefore,

$$
\lim _{i \rightarrow \infty}\left\|x_{n_{i}}-J_{\lambda_{0}}\left(I-\lambda_{0} A\right) x_{n_{i}}\right\|=0 .
$$

Since $J_{\lambda_{0}}\left(I-\lambda_{0} A\right)$ is nonexpansive and $x_{n_{i}} \rightarrow p$, Lemma 7 gives $p \in \operatorname{Fix}\left(J_{\lambda_{0}}\left(I-\lambda_{0} A\right)\right)$; that is, $p \in(A+B)^{-1} 0$. Thus, we have $p \in \Omega$.

By (29) and the property of metric projection, we have

$$
\begin{aligned}
\limsup _{n \rightarrow \infty}\left\langle u-\bar{x}, x_{n}-\bar{x}\right\rangle & =\lim _{i \rightarrow \infty}\left\langle u-\bar{x}, x_{n_{i}}-\bar{x}\right\rangle \\
& =\langle u-\bar{x}, p-\bar{x}\rangle \leq 0 .
\end{aligned}
$$

Inequality (28) arrives.
Finally, we prove that $x_{n} \rightarrow \bar{x}$. Using (14) again, we obtain

$$
\begin{aligned}
\left\|x_{n+1}-\bar{x}\right\|^{2} \leq & \beta_{n}\left\|x_{n}-\bar{x}\right\|^{2}+\left(1-\beta_{n}\right)\left\|y_{n}-\bar{x}\right\|^{2} \\
\leq & \beta_{n}\left\|x_{n}-\bar{x}\right\|^{2}+\left(1-\beta_{n}\right) \\
& \times\left[\left(1-\alpha_{n}\right)^{2}\left\|x_{n}-\bar{x}\right\|^{2}+2 \alpha_{n}\left\langle u_{n}-\bar{x}, y_{n}-\bar{x}\right\rangle\right] \\
\leq & {\left[1-\alpha_{n}\left(1-\beta_{n}\right)\right]\left\|x_{n}-\bar{x}\right\|^{2}+2 \alpha_{n}\left(1-\beta_{n}\right) } \\
& \times\left(\left\langle u_{n}-u, y_{n}-\bar{x}\right\rangle\right. \\
& \left.\quad+\left\langle u-\bar{x}, y_{n}-x_{n}\right\rangle+\left\langle u-\bar{x}, x_{n}-\bar{x}\right\rangle\right) .
\end{aligned}
$$

Note that

$$
\limsup _{n \rightarrow \infty}\left\langle u-\bar{x}, x_{n}-\bar{x}\right\rangle \leq 0 .
$$

It follows from Lemma 8 that $\left\{x_{n}\right\}$ converges strongly to $\bar{x}$. 9.

The following results are direct consequences of Theorem

Corollary 10. Let $C$ be a nonempty closed convex subset of a real Hilbert space $H$ and $A$ an $\alpha$-inverse strongly monotone operator of $C$ into $H$ with $\alpha>0$. Suppose that $B$ is a maximal monotone operator on $H$ with $(A+B)^{-1} 0 \neq \emptyset$. Let $\left\{\alpha_{n}\right\}$ and $\left\{\beta_{n}\right\}$ be sequences in $(0,1)$ and let $\left\{u_{n}\right\}$ be a sequence in $H$. Let $\left\{x_{n}\right\}$ be a sequence generated by

$$
\begin{gathered}
x_{1} \in C \text { chosen arbitrarily, } \\
y_{n}=\alpha_{n} u_{n}+\left(1-\alpha_{n}\right) J_{\lambda_{n}}\left(I-\lambda_{n} A\right) x_{n}, \\
x_{n+1}=\beta_{n} x_{n}+\left(1-\beta_{n}\right) P_{C} y_{n} .
\end{gathered}
$$

If conditions (c1)-(c3) and (c5) are satisfied, then the sequence $\left\{x_{n}\right\}$ converges strongly to $P_{(A+B)^{-1} 0} u$.

Proof. Letting $f(x, y) \equiv 0$ for all $x, y \in C$ and $r_{n}=1$ in Theorem 9, the desired result follows.

Remark 11. When $u_{n} \equiv u \in C$, the algorithm in Corollary 10 corresponds to the one in Theorem 10 of Takahashi et al. [12]. Thus, Corollary 10 includes, as a special case, Theorem 10 of [12].

Corollary 12. Let $C$ be a nonempty closed convex subset of a real Hilbert space $H$ and let $f$ be a bifunction from $C \times C$ to $\mathbb{R}$ with (A1)-(A4). Assume that the set $E P(f)$ is nonempty. Let $\left\{\alpha_{n}\right\}$ and $\left\{\beta_{n}\right\}$ be sequences in $(0,1)$ and let $\left\{u_{n}\right\}$ be a sequence in $H$. Let $\left\{x_{n}\right\}$ be a sequence generated by

$$
x_{1} \in C \text { chosen arbitrarily, }
$$

$$
y_{n}=\alpha_{n} u_{n}+\left(1-\alpha_{n}\right) x_{n},
$$




$$
\begin{gathered}
z_{n} \in C, \text { such that } f\left(z_{n}, y\right)+\frac{1}{r_{n}}\left\langle y-z_{n}, z_{n}-y_{n}\right\rangle \geq 0, \\
\forall y \in C, \\
x_{n+1}=\beta_{n} x_{n}+\left(1-\beta_{n}\right) z_{n} .
\end{gathered}
$$

If conditions (c1)-(c4) are satisfied, then the sequence $\left\{x_{n}\right\}$ converges strongly to $P_{E P(f)} u$.

Proof. Putting $A=0, B=\partial \delta_{C}$ (i.e., the subdifferential of the indicator function of $C$ ) in Theorem 9, we get the result.

\section{Applications}

In this section, we apply the results in the preceding section to variational inequality and optimization problems.

Now we consider the variational inequality problem. Let $H$ be a real Hilbert space and let $f$ be a proper lower semicontinuous convex function of $H$ into $(-\infty,+\infty]$. Then, the subdifferential $\partial f$ of $f$ is defined as follows:

$$
\partial f(x)=\{z \in H: f(y)-f(x) \geq\langle z, y-x\rangle, \forall y \in H\}
$$

for all $x \in H$. Rockafellar [18] claimed that $\partial f$ is a maximal monotone operator. Let $\delta_{C}$ be the indicator function of $C$; that is,

$$
\delta_{C}(x)= \begin{cases}0, & x \in C \\ +\infty, & x \notin C\end{cases}
$$

Since $\delta_{C}$ is a proper lower semicontinuous convex function on $H$, the subdifferential $\partial \delta_{C}$ of $\delta_{C}$ is a maximal monotone operator. The resolvent $J_{\lambda}$ of $\partial \delta_{C}$ for $\lambda>0$ is defined by

$$
J_{\lambda} x=\left(I+\lambda \partial \delta_{C}\right)^{-1} x, \quad \forall x \in H .
$$

We have

$$
\begin{aligned}
u= & J_{\lambda} x=\left(I+\lambda \partial \delta_{C}\right)^{-1} x \Longleftrightarrow x \in u+\lambda \partial \delta_{C} u \\
& \Longleftrightarrow x \in u+\lambda N_{C} u \Longleftrightarrow x-u \in \lambda N_{C} u \\
& \Longleftrightarrow \frac{1}{\lambda}\langle x-u, y-u\rangle \leq 0 \quad \forall y \in C \\
& \Longleftrightarrow\langle x-u, y-u\rangle \leq 0 \quad \forall y \in C \\
& \Longleftrightarrow u=P_{C} x,
\end{aligned}
$$

where $N_{C} u=\{z \in H:\langle z, y-u\rangle \leq 0$, for all $y \in C\}$.

Let $A: C \rightarrow H$ be a nonlinear mapping. The variational inequality problem for $A$ is to find $z \in C$ such that

$$
\langle A z, y-z\rangle \geq 0, \quad \forall y \in C \text {. }
$$

The set of its solutions is denoted by $\operatorname{VI}(A, C)$. It is easy to see that $V I(A, C)=\left(A+\partial \delta_{C}\right)^{-1} 0$ (for more details, see [13]). Using Corollary 10, we obtain the strong convergence theorem for the variational inequality problem.

Theorem 13. Let $C$ be a nonempty closed convex subset of a real Hilbert space $H$ and $A$ an $\alpha$-inverse strongly monotone operator of $C$ into $H$ with $\alpha>0$. Assume that the set $V I(A, C)$ is nonempty. Let $\left\{\alpha_{n}\right\}$ and $\left\{\beta_{n}\right\}$ be sequences in $(0,1)$ and let $\left\{u_{n}\right\}$ be a sequence in $H$. Let $\left\{x_{n}\right\}$ be a sequence generated by

$$
\begin{gathered}
x_{1} \in C \text { chosen arbitrarily, } \\
y_{n}=\alpha_{n} u_{n}+\left(1-\alpha_{n}\right) P_{C}\left(I-\lambda_{n} A\right) x_{n}, \\
x_{n+1}=\beta_{n} x_{n}+\left(1-\beta_{n}\right) P_{C} y_{n} .
\end{gathered}
$$

If conditions (c1)-(c3) and (c5) are satisfied, then the sequence $\left\{x_{n}\right\}$ converges strongly to $P_{V I(A, C)} u$.

Proof. Notice that $\operatorname{VI}(A, C)=\left(A+\partial \delta_{C}\right)^{-1} 0$. Corollary 10 yields the conclusion.

Next we study the optimization problem

$$
\begin{gathered}
\min g(x), \\
x \in C,
\end{gathered}
$$

where $g(x)$ is a proper lower semicontinuous convex function of $H$ into $(-\infty,+\infty]$ such that $C$ is contained in $\operatorname{dom} g=\{x \in$ $H: g(x)<+\infty\}$. We denote by $\operatorname{Sol}(g, C)$ the set of solutions of problem (51). Let $f: C \times C \rightarrow \mathbb{R}$ be a bifunction defined by

$$
f(x, y)=g(y)-g(x) .
$$

It is clear that $f(x, y)$ satisfies (A1)-(A4) and $E P(f)=$ $\operatorname{Sol}(g, C)$. Therefore, by Corollary 12 , the following result is obtained.

Theorem 14. Let $g(x)$ be a proper lower semicontinuous convex function of $H$ into $(-\infty,+\infty]$ and let $C$ be a nonempty closed convex subset of $H$ such that $C$ is contained in dom $g$. Suppose that the set $\operatorname{Sol}(g, C)$ is nonempty. Let $\left\{\alpha_{n}\right\}$ and $\left\{\beta_{n}\right\}$ be sequences in $(0,1)$ and let $\left\{u_{n}\right\}$ be a sequence in $H$. Let $\left\{x_{n}\right\}$ be a sequence generated by

$$
\begin{gathered}
x_{1} \in C \text { chosen arbitrarily, } \\
y_{n}=\alpha_{n} u_{n}+\left(1-\alpha_{n}\right) x_{n}, \\
z_{n}=\arg \min _{y \in C}\left\{g(y)+\frac{1}{2 r_{n}}\left\|y-y_{n}\right\|^{2}\right\}, \\
x_{n+1}=\beta_{n} x_{n}+\left(1-\beta_{n}\right) z_{n} .
\end{gathered}
$$

If conditions (c1)-(c4) are satisfied, then the sequence $\left\{x_{n}\right\}$ converges strongly to $P_{\mathrm{Sol}(g, C)} u$.

Proof. Letting $f(x, y)=g(y)-g(x)$ in Corollary 12, we get the required result. 
Remark 15. Letting $0=u=\lim _{n \rightarrow \infty} u_{n}$ in our results, we obtain the algorithms for minimal-norm solutions of corresponding problems.

\section{Conflict of Interests}

The authors declare that there is no conflict of interests.

\section{Acknowledgments}

The authors would like to thank the referees and editors for their valuable comments and suggestions. The work was supported by graduate funds of Beijing University of Technology (no. ykj-2013-9422).

\section{References}

[1] E. Blum and W. Oettli, "From optimization and variational inequalities to equilibrium problems," The Mathematics Student, vol. 63, no. 1-4, pp. 123-145, 1994.

[2] C. S. Chuang, L. J. Lin, and W. Takahashi, "Halpern's type iterations with perturbations in Hilbert spaces: equilibrium solutions and fixed points," Journal of Global Optimization, vol. 56, no. 4, pp. 1591-1601, 2013.

[3] P. Sunthrayuth and P. Kumam, "A new computational technique for common solutions between systems of generalized mixed equilibrium and fixed point problems," Journal of Applied Mathematics, vol. 2013, Article ID 230392, 17 pages, 2013.

[4] P. L. Combettes and S. A. Hirstoaga, "Equilibrium programming in Hilbert spaces," Journal of Nonlinear and Convex Analysis, vol. 6, no. 1, pp. 117-136, 2005.

[5] D. N. Qu and C. Z. Cheng, "A strong convergence theorem on solving common solutions for generalized equilibrium problems and fixed-point problems in Banach space," Fixed Point Theory and Applications, vol. 2011, article 17, 2011.

[6] F. Cianciaruso, G. Marino, and L. Muglia, "Iterative methods for equilibrium and fixed point problems for nonexpansive semigroups in Hilbert spaces," Journal of Optimization Theory and Applications, vol. 146, no. 2, pp. 491-509, 2010.

[7] R. T. Rockafellar, "Monotone operators and the proximal point algorithm," SIAM Journal on Control and Optimization, vol. 14, no. 5, pp. 877-898, 1976.

[8] O. Güler, "On the convergence of the proximal point algorithm for convex minimization," SIAM Journal on Control and Optimization, vol. 29, no. 2, pp. 403-419, 1991.

[9] S. Kamimura and W. Takahashi, "Approximating solutions of maximal monotone operators in Hilbert spaces," Journal of Approximation Theory, vol. 106, no. 2, pp. 226-240, 2000.

[10] H. K. Xu, "A regularization method for the proximal point algorithm," Journal of Global Optimization, vol. 36, no. 1, pp. 115125, 2006.

[11] K. Aoyama, Y. Kimura, W. Takahashi, and M. Toyoda, "On a strongly nonexpansive sequence in Hilbert spaces," Journal of Nonlinear and Convex Analysis, vol. 8, no. 3, pp. 471-489, 2007.

[12] W. Takahashi, N. C. Wong, and J. C. Yao, "Two generalized strong convergence theorems of Halpern's type in Hilbert spaces and applications," Taiwanese Journal of Mathematics, vol. 16, no. 3, pp. 1151-1172, 2012.

[13] L. J. Lin and W. Takahashi, "A general iterative method for hierarchical variational inequality problems in Hilbert spaces and applications," Positivity, vol. 16, no. 3, pp. 429-453, 2012.
[14] S. Takahashi, W. Takahashi, and M. Toyoda, "Strong convergence theorems for maximal monotone operators with nonlinear mappings in Hilbert spaces," Journal of Optimization Theory and Applications, vol. 147, no. 1, pp. 27-41, 2010.

[15] T. Suzuki, "Strong convergence theorems for infinite families of nonexpansive mappings in general Banach spaces," Fixed Point Theory and Applications, vol. 2005, article 103, 2005.

[16] H. H. Bauschke and P. L. Combettes, Convex Analysis and Monotone Operator Theory in Hilbert Spaces, Springer, 2011.

[17] H. K. Xu, "Another control condition in an iterative method for nonexpansive mappings," Bulletin of the Australian Mathematical Society, vol. 65, no. 1, pp. 109-113, 2002.

[18] R. T. Rockafellar, "On the maximal monotonicity of subdifferential mappings," Pacific Journal of Mathematics, vol. 33, no. 1, pp. 209-216, 1970 . 


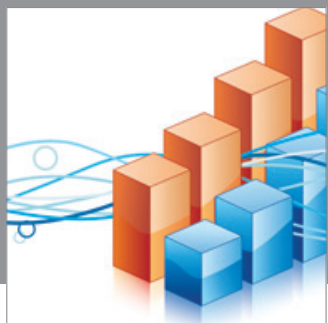

Advances in

Operations Research

mansans

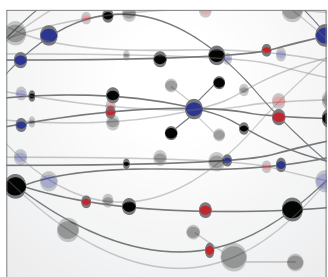

The Scientific World Journal
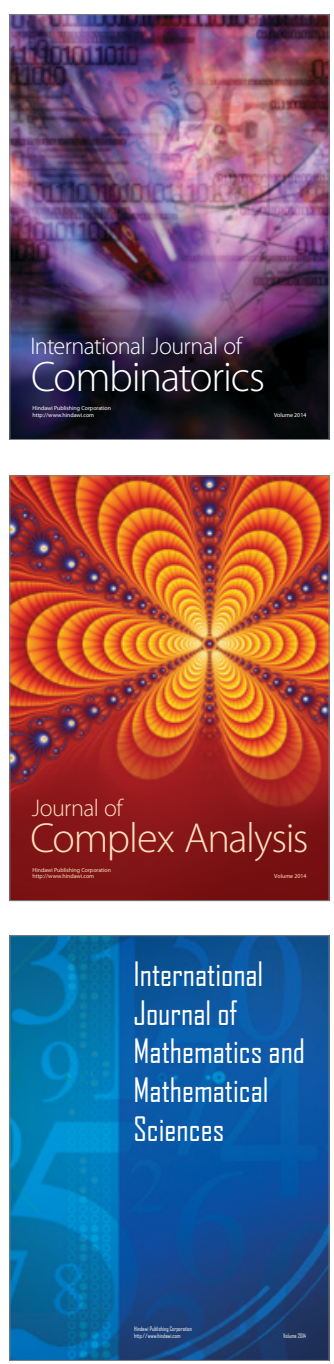
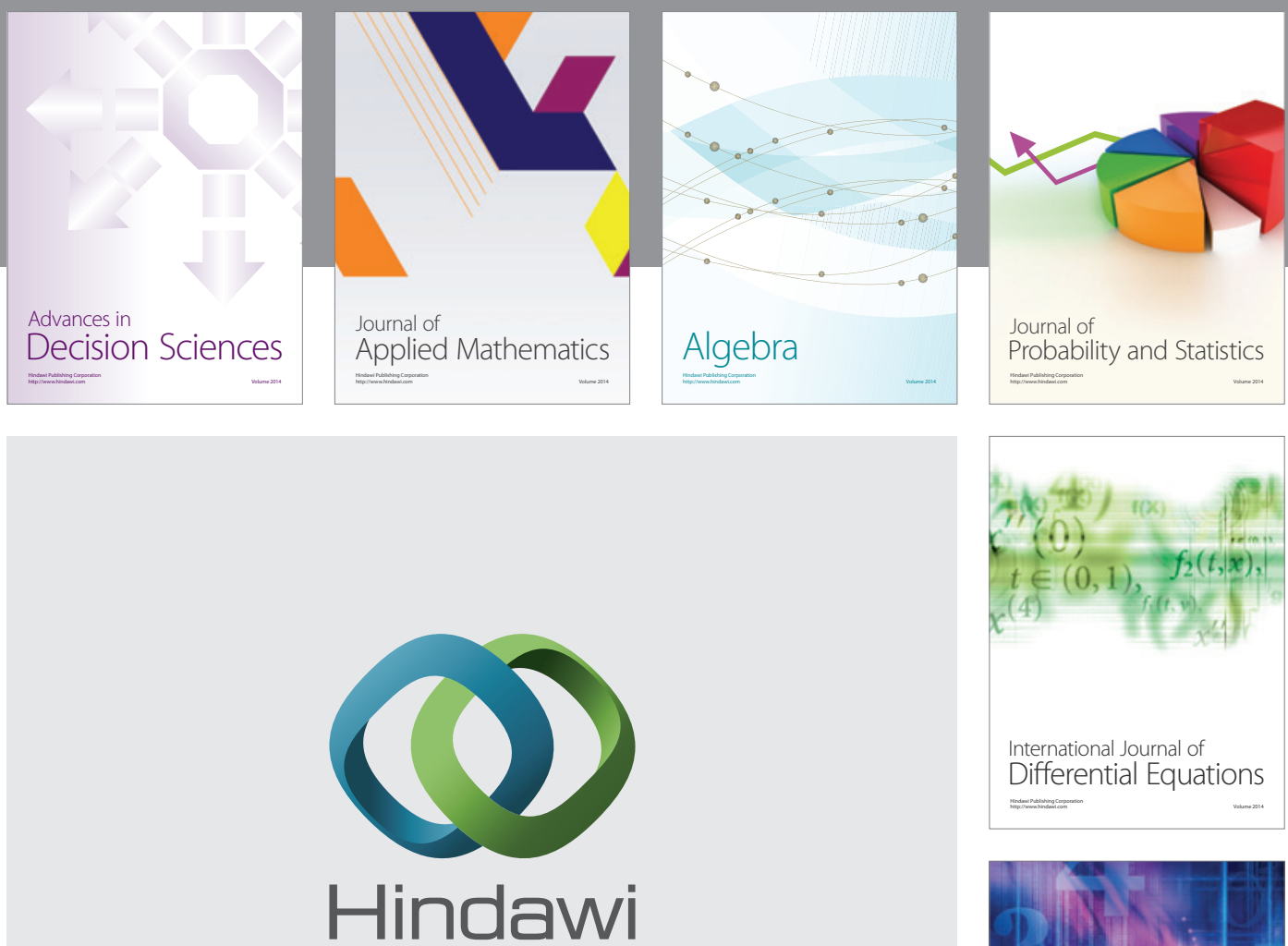

Submit your manuscripts at http://www.hindawi.com
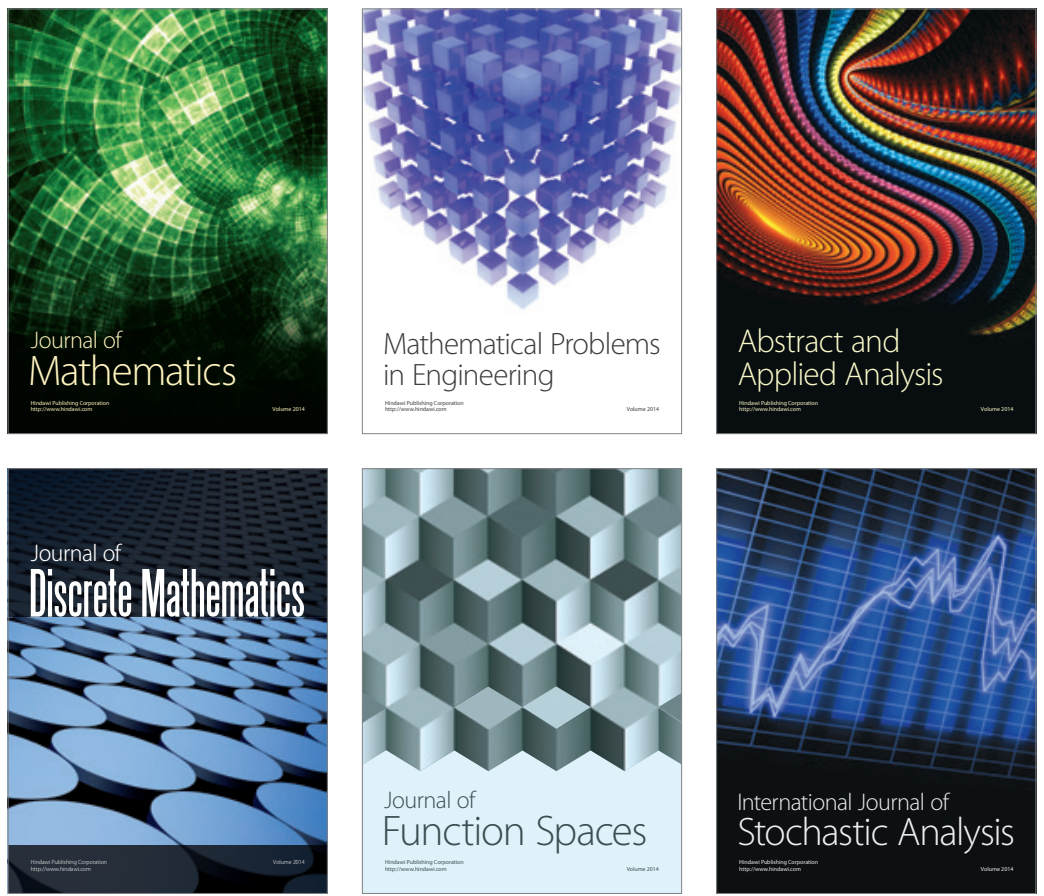

Journal of

Function Spaces

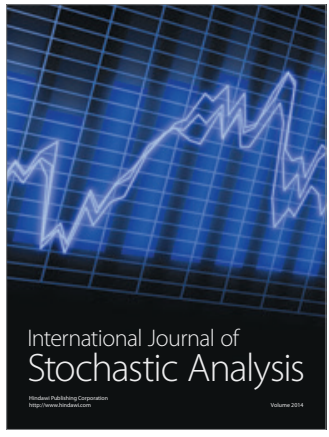

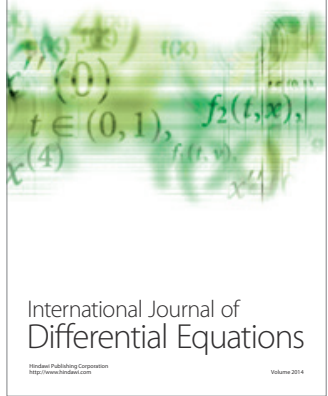
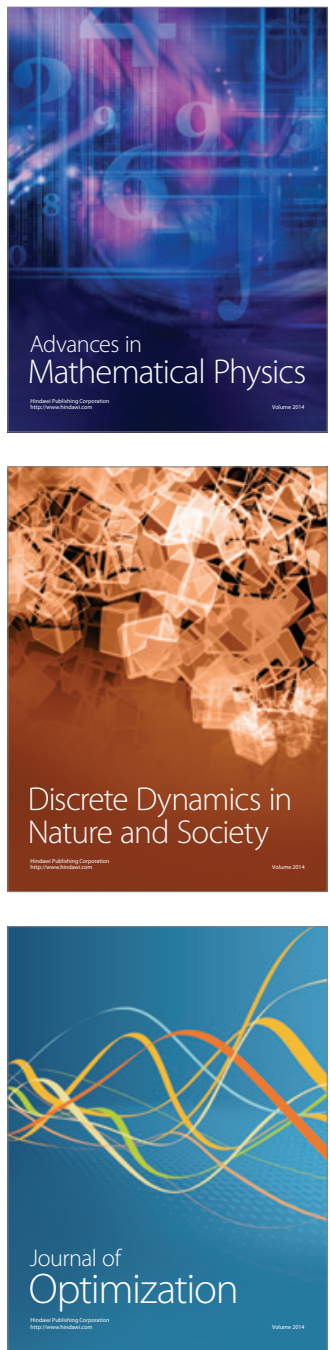